\title{
Prospecção de moluscos bivalves no estudo da poluição dos rios Cachoeira e Santana em Ilhéus, Bahia, Brasil
}

\author{
Bivalve molluscs prospection in pollution study from Cachoeira and Santana rivers in Ilheus, \\ Bahia, Brazil
}

\author{
Denise SANDE'; Tauá A. MELO²; Gílvia Simone Andrade OLIVEIRA ${ }^{1}$, Lidiane BARRETO²; \\ Teddy TALBOT ${ }^{2}$; Guisla BOEHS ${ }^{3}$; João Luciano ANDRIOLI ${ }^{3}$
}

\begin{abstract}
${ }^{1}$ Programa de Pós-graduação em Biologia e Biotecnologia de Microrganismos da Universidade Estadual de Santa Cruz, Ilhéus-BA ${ }^{2}$ Laboratório de Microbiologia da Universidade Estadual de Santa Cruz, Ilhéus-BA

${ }^{3}$ Departamento de Ciências Biológicas da Universidade Estadual de Santa Cruz, Ilhéus-BA
\end{abstract}

\begin{abstract}
Resumo
Um levantamento sobre o nível de poluição dos Rios Cachoeira e Santana (Ilhéus, Bahia, Brasil) foi realizado durante um trimestre, por meio da avaliação da qualidade microbiológica da água e de frutos do mar (Crassostrea rhizophorae - ostra-do-mangue e Tagelus plebeius - moapem) extraídos desses rios. Tradicionais indicadores de poluição como coliformes totais $(\mathrm{Ct})$ e coliformes termotolerantes $(\mathrm{CT})$, além de contagem padrão de microrganismos, com isolamento e identificação das enterobactérias, foram determinados nas amostras dos rios, os quais exibiram diferentes níveis de poluição fecal. Foram isolados 68 microrganismos, distribuídos em dez espécies, dentre elas, Salmonella typhi, Escherichia coli e Shigella sp., alertando para o risco do consumo in natura desses moluscos, mesmo quando em conformidade com a legislação estabelecida para CT. A prospecção de moluscos para o acompanhamento dos índices de poluição não se mostrou efetiva considerando a pesquisa de CT em ostras e moapens. Verificou-se também o maior grau de contaminação no Rio Cachoeira, o qual serve de base para distribuição de água na região e como fonte de subsistência, por meio da atividade extrativista, para a população ribeirinha.
\end{abstract}

Palavras-chave: Qualidade da água. Moluscos bivalves. Poluição. Coliformes termotolerantes. Enteróbios patogênicos.

\begin{abstract}
A survey about the pollution level of the Cachoeira and Santana Rivers (Ilheus, Bahia, Brazil) was performed for a quarter, through the assessment of the microbiological quality of water and seafood (Crassostrea rhizophorae - oyster and Tagelus plebeius - razor clam) extracted from these rivers. Traditional indicators of pollution such as total coliforms $(\mathrm{Ct})$ and thermtolerant coliforms (CT), and total count of micro-organisms, with isolation and identification of Enterobacteriaceae were determined in rivers samples, which exhibited different levels of faecal pollution. An amount of 68 micro-organisms was isolated, distributed in ten species, among them, Salmonella typhi, Escherichia coli and Shigella sp., warning about the risk of consuming these shellfish in nature, even when there is accordance with the laws established for CT. The bivalve prospection to monitor pollution levels was not effective considering CT detection in oysters and moapens. There was also the highest contamination degree in the Cachoeira River, which is used for water distribution in the region and as livelihood source through extractive activities for the riverside population.
\end{abstract}

Keywords: Quality of water. Bivalve molluscs. Pollution. Thermtolerant coliforms. Pathogenic enterobacteria.

\section{Introdução}

A contaminação de águas dos rios, lagos e mares por esgotos urbanos não tratados e dejetos industriais (formas mais prevalentes), além de produtos químicos, é responsável pela degradação dos recursos hídricos do Brasil e da maioria dos países do mundo ${ }^{1}$.
Correspondência para:

João Luciano Andrioli

Departamento de Ciências Biológicas - UESC, Rod. Ilhéus-Itabuna, Km 16, Ilhéus-BA, 45650-000, Brazil

Fone: 0115573680 5105/ fax: 0115573680 5226,

E-mail: joaoluciano2002@yahoo.com.br

Recebido: 25/08/2009

Aprovado: 04/03/2010 
Os rios Cachoeira e Santana têm importância fundamental para o município de Ilhéus (BA) e, apesar de serem utilizados na higienização corporal, doméstica, em atividades recreativas e como fonte pesqueira para alimentação e renda das populações ribeirinhas, recebem continuamente, em suas águas, grandes quantidades de esgotos in natura ${ }^{1}$, sobretudo provenientes de fossas e valas ${ }^{2}$.

A coleta de moluscos nessa região ocorre de forma extrativista, estendendo-se, geralmente, durante todo o ano. Não há regulamentação legal ou mesmo instrução normativa por parte dos órgãos ambientais estaduais e municipais para sua captura. Existem, no entanto, resoluções e portarias nacionais que regulamentam e estabelecem padrões de qualidade indispensáveis, para que a água e os bivalves possam ser utilizados pelo homem com segurança, sem agravos à saúde 3 .

Segundo Pruzzo, Gallo e Canesi ${ }^{4}$, bivalves marinhos estão distribuídos ao longo do ambiente costeiro e, devido ao seu hábito alimentar filtrador, podem acumular grande número de bactérias, parasitos ${ }^{5}$ e metais pesados $^{6}$. Estes animais filtram 19 a $50 \mathrm{~L}$ de água por hora, com pouca ou nenhuma capacidade seletiva ${ }^{7}$. Em ostras, por exemplo, grande percentual das bactérias ingeridas sobrevive ao processo digestivo devido à adaptação ao ambiente marinho, aos mecanismos de resistência associados à degradação enzimática e ao uso do ambiente intestinal do hospedeiro como fonte nutricional por esses microrganismos ${ }^{8,9,10}$.

Muitos surtos alimentares em humanos são decorrentes do consumo in natura de frutos do mar que, ingeridos sem o conveniente processamento térmico, podem levar microrganismos patogênicos ao trato gastrointestinal do homem ${ }^{11,12}$. Os moluscos bivalves são os maiores acumuladores de poluentes do meio ambiente, destacando-se como bioindicadores da insalubridade da água ${ }^{5}$. Os principais testes realizados em moluscos para indicar a qualidade microbiológica das águas são a quantificação dos coliformes totais $(\mathrm{Ct})$ e termotolerantes (CT).
O objetivo deste trabalho foi avaliar a contaminação nos rios Cachoeira e Santana no município de Ilhéus (BA), por meio da análise microbiológica dos moluscos Crassostrea rhizophorae (ostra-do-mangue) e $\mathrm{Ta}$ gelus plebeius (moapem) desses locais.

\section{Material e Método}

Os Rios Cachoeira e Santana (Ilhéus, Bahia, Brasil), identificados como pontos de coleta A e B (Figura 1), correspondem às coordenadas $14^{\circ} 49^{\prime} 63^{\prime \prime} \mathrm{S}$

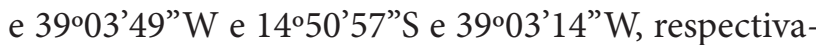
mente. Foram realizadas sete coletas quinzenais, entre maio e julho de 2006. A cada coleta, captavam-se $500 \mathrm{~mL}$ de água corrente a $50 \mathrm{~cm}$ de profundidade e a aproximadamente $4 \mathrm{~m}$ das margens dos rios, em áreas próximas aos bancos de areia, de onde eram retirados os moapens (250 g). As ostras (250 g) foram apanhadas de árvores do mangue situadas próximas às margens. As amostras eram acondicionadas a $4{ }^{\circ} \mathrm{C}$ e encaminhadas para o laboratório de Microbiologia da Universidade Estadual de Santa Cruz - UESC, onde eram imediatamente processadas.

Aproximadamente 15 conchas dos espécimes foram lavadas em água corrente, escovadas e enxaguadas em etanol 70\% e em água destilada para limpar sujidades e debris celulares, sendo que somente os moluscos com valvas fechadas foram utilizados. Em seguida, os moluscos foram abertos para a retirada do conteúdo intervalvar, o qual foi triturado, homogeneizado e separado em duas alíquotas, uma de $25 \mathrm{~g}$ e outra de $1 \mathrm{~g}$ de cada espécie, separadamente, para as análises.

A contagem de bactérias aeróbias heterotróficas mesofílicas (contagem padrão em placa) foi feita a partir da diluição seriada de $1 \mathrm{~g}$ (por espécie de molusco) ou $1 \mathrm{~mL}$ (água homogeneizada) de amostra em $9 \mathrm{~mL}$ de solução fisiológica $(0,85 \%$ de $\mathrm{NaCl}$ ) e inoculação spread plate de $0,1 \mathrm{~mL}$ em meio Total Count Plate - Merck.

O plaqueamento também foi feito sobre meio MacConkey (Himedia) para isolamento e identificação 


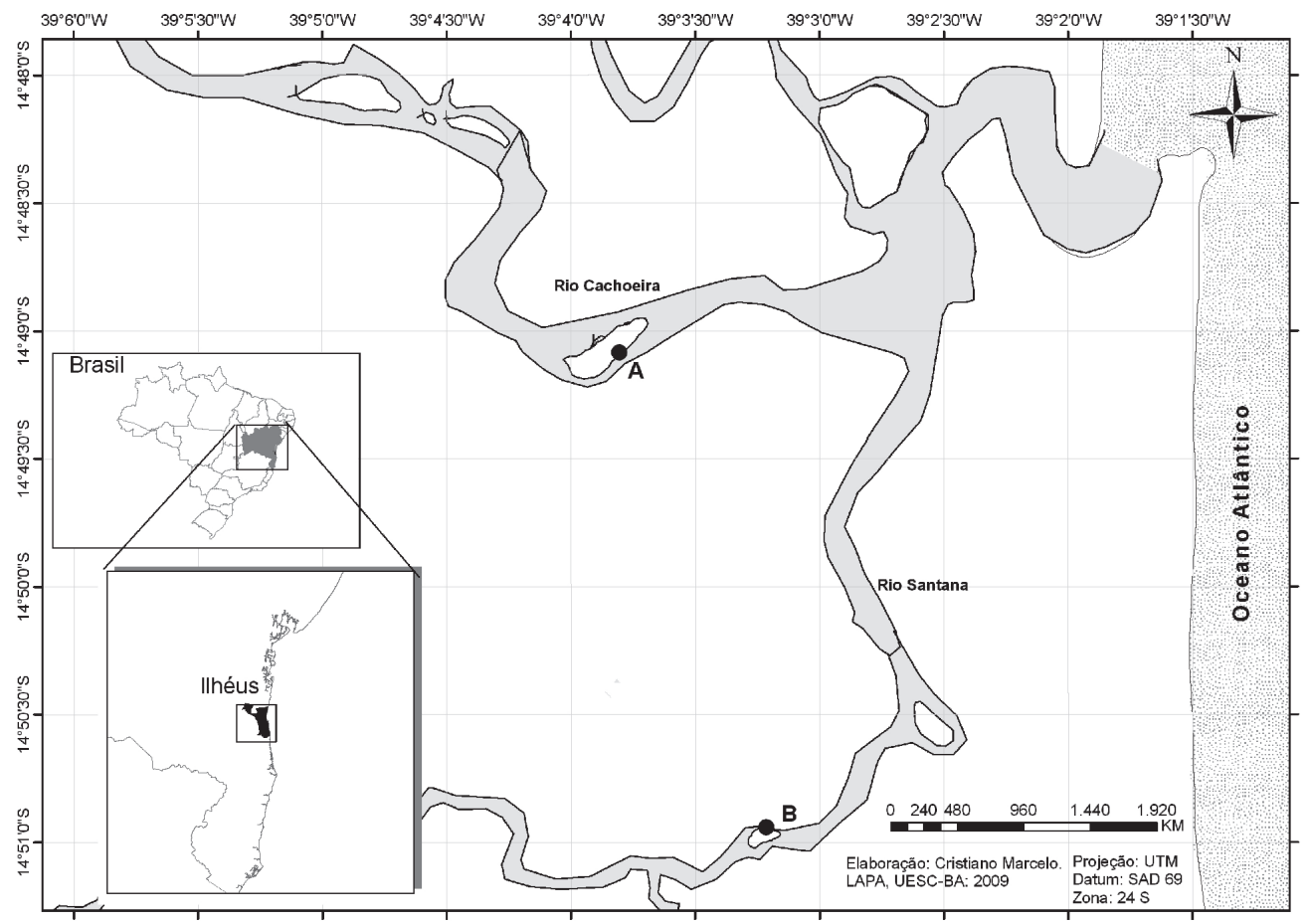

Figura 1 - Pontos de coleta dos Rios Cachoeira e Santana em Ilhéus, Bahia

das enterobactérias patogênicas presentes nos rios. Os morfotipos encontrados foram identificados bioquimicamente através das provas Tríplice Sugar Iron -TSI (Himedia), citrato (Himedia), urease $(0,5 \mathrm{~g}$ de $\mathrm{NH}_{4} \mathrm{H}_{2} \mathrm{PO}_{4}$ - fosfato de diidrogênio de amônio, 0,5 $\mathrm{g}$ de $\mathrm{K}_{2} \mathrm{HPO}_{4}$ - fosfato hidrogênio dipotássico, 0,2 $\mathrm{g}$ de $\mathrm{MgSO}_{4} .7 \mathrm{H}_{2} \mathrm{O}$ (sulfato de magnésio heptaidratado), $5 \mathrm{~g}$ de $\mathrm{NaCl}, 1 \mathrm{~g}$ de extrato de levedura, $16 \mathrm{mg}$ de Vermelho de Cresol, $800 \mathrm{~mL}$ de água destilada), meio Sulphide Indol Motility - SIM (Himedia) e meio Phenylalanine Agar (Himedia). Os resultados foram comparados com as chaves de identificação do Manual de Bergey ${ }^{13}$.

No teste de coliformes totais (Ct), utilizou-se a técnica de Número Mais Provável (NMP) em série de cinco tubos. Para os moluscos, utilizaram-se $25 \mathrm{~g}$ de cada espécie, separadamente, em $225 \mathrm{~mL}$ de água peptonada $0,1 \%$ para realizar a diluição $10^{-1}$, a partir da qual foram feitas as diluições $10^{-2}$ e $10^{-3}$. Para a água, homogeneizaram-se $250 \mathrm{~mL}$ e reservaram-se
$50 \mathrm{~mL}$ para as análises. Para a prova presuntiva de coliformes, utilizaram-se três séries com cinco tubos cada, contendo $10 \mathrm{~mL}$ de caldo lactosado. A primeira série, concentração dupla, recebeu $10 \mathrm{~mL}$ da amostra de água ou 1,0 $\mathrm{mL}$ da amostra de bivalve $\left(10^{-1}\right)$. As outras duas séries, com concentração simples, receberam alíquotas de 1,0 e 0,1 $\mathrm{mL}$ de amostra de água ou 1,0 $\mathrm{mL}$ de amostra de bivalve $\left(10^{-2} \mathrm{e} 10^{-3}\right)$, respectivamente. Os tubos foram incubados em estufa a $35 \pm 0,5^{\circ} \mathrm{C}$ por $24 \pm 2 \mathrm{~h}$.

Alíquotas dos tubos positivos de caldo lactosado foram inoculadas em tubos contendo Caldo Verde Brilhante - VB (Merck) (incubados a $35 \pm 0,5{ }^{\circ} \mathrm{C}$ por $24 \pm 2 \mathrm{~h}$ ) e em tubos contendo caldo EC (Merck) (incubados em banho-maria com agitação, 44,5 $\pm 0,2{ }^{\circ} \mathrm{C}$ por $24 \pm 2 \mathrm{~h}$ ) para confirmação de Ct e CT, respectivamente. A positividade nos testes presuntivos para Ct e CT foi indicada mediante crescimento microbiano nos tubos de ensaio e presença de gás nos tubos de Durham. 
Por meio da combinação do número de tubos positivos em cada série de diluição, nos testes para $\mathrm{Ct}$ e CT, bem como sua comparação com a tabela de $\mathrm{NMP}^{14}$, obteve-se NMP de coliformes totais e termotolerantes/ $100 \mathrm{~mL}$ de água ou por $100 \mathrm{~g}$ de amostra. Os testes utilizados foram correlação, teste $t$ não pareado e ANOVA one way, através do programa estatístico Graphpad prism 5.0, com intervalo de confiança de 95\% (GraphPad Software Inc, 2007).

\section{Resultados e Discussão}

O rio Cachoeira demonstrou uma contagem padrão em placas superior às contagens do rio Santana, mas não foi encontrada diferença significativa entre eles na contaminação (Tabela 1). Para Salán ${ }^{15}$, essa técnica de contagem de bactérias aeróbias heterotróficas mesófilas é importante para a avaliação do nível de poluição ambiental dos ecossistemas aquáticos, pois estima a densidade de microrganismos poluidores em águas não potáveis, reforçando a avaliação da sua qualidade. Nesse estudo, a quantificação total de bactérias variou de $105\left(1 \mathrm{X} \mathrm{10} 0^{2}\right)$ a $375\left(3,75 \times 10^{2}\right) \mathrm{UFC} /$ $\mathrm{mL}$ para o rio Cachoeira e de $35\left(0,35 \times 10^{2}\right)$ a 335 $\left(3,3 \times 10^{2}\right)$ UFC/mL para o rio Santana, em contraste com os dados apresentados por Schneider et al. ${ }^{16}$, que encontraram em estudo com amostras de águas superficiais do rio Suruvi (SC) uma oscilação superior $\left(1,3 \times 10^{3}\right.$ a $\left.1,2 \times 10^{6} \mathrm{UFC} / \mathrm{mL}\right)$, caracterizando uma contaminação microbiana menos acentuada nos rios Cachoeira e Santana.

Todavia, um maior índice de contaminação do rio Cachoeira em relação ao rio Santana foi demonstrado significativamente $(\mathrm{p} \leq 0,05)$ pelas análises de Ct das águas dos rios (Tabela 1), assim como pelas análises de CT tanto das águas (Figura 2) quanto dos moluscos avaliados (Tabela 2). A maior contaminação do rio Cachoeira está, muito provavelmente, relacionada à diferença da quantidade e qualidade de despejos de esgotos domésticos e industriais não tratados recebi-
Tabela 1 - Contagem padrão em placa (CPP), Número Mais Provável (NMP/100 mL) de coliformes totais (Ct) das águas do Rio Cachoeira (AC) e Santana (AS), Ilhéus-BA - maio a julho de 2006

\begin{tabular}{|c|c|c|c|c|}
\hline \multirow[b]{3}{*}{ Coleta } & \multicolumn{2}{|c|}{ CPP } & \multicolumn{2}{|c|}{$\mathrm{Ct}$} \\
\hline & \multicolumn{2}{|c|}{ (UFC/ml) } & \multicolumn{2}{|c|}{$\mathrm{NMP} / 100 \mathrm{ml}$} \\
\hline & $\mathrm{AC}$ & AS & $\mathrm{AC}$ & AS \\
\hline $2 / 5 / 2006$ & 160 & 190 & $1,7 \times 10^{2}$ & $0,8 \times 10^{2}$ \\
\hline $15 / 5 / 2006$ & 105 & 35 & $2,2 \times 10^{2}$ & $1,7 \times 10^{2}$ \\
\hline $29 / 5 / 2006$ & 315 & 240 & $1,7 \times 10^{2}$ & $1,3 \times 10^{2}$ \\
\hline $12 / 6 / 2006$ & 375 & 335 & $1,7 \times 10^{2}$ & $1,1 \times 10^{2}$ \\
\hline $26 / 6 / 2006$ & 310 & 160 & $1,4 \times 10^{2}$ & $0,8 \times 10^{2}$ \\
\hline $10 / 7 / 2006$ & 140 & 300 & $1,3 \times 10^{2}$ & $0,9 \times 10^{2}$ \\
\hline $24 / 07 / 2006$ & 235 & 210 & $1,4 \times 10^{2}$ & $1,1 \times 10^{2}$ \\
\hline Médias & $234,3 a$ & $210,0^{a}$ & $1,63 \times 10^{2 b}$ & $1,1 \times 10^{2 b}$ \\
\hline
\end{tabular}

a Não há diferença significativa ( $\mathrm{p}=0,6594 ; \mathrm{GL}=12$ e $\left.\mathrm{t}_{\mathrm{ctr}}=0,4519\right)$;

b Há diferença significativa $\left(\mathrm{p}=0,0082 ; \mathrm{GL}=12\right.$ e $\left.\mathrm{t}_{\mathrm{crt}}=3,161\right)$.

Tabela 2 - Número Mais Provável (NMP/100 g) de coliformes termotolerantes (CT) dos moluscos Crassostrea rhizophorae (ostra) e Tagelus plebeius (moapem) dos Rios Cachoeira e Santana, Ilhéus-BA, maio a julho de 2006. OC - ostra do Cachoeira; MC moapem do Cachoeira; OS - ostra do Santana; e MS - moapem do Santana

\begin{tabular}{ccccc}
\hline & \multicolumn{4}{c}{ CT } \\
\cline { 2 - 5 } Coleta & OC & OS & MC & MS \\
\hline $2 / 5 / 2006$ & $1,1 \times 10^{1}$ & $4 \times 10^{0}$ & $1,7 \times 10^{1}$ & $1,1 \times 10^{1}$ \\
$15 / 5 / 2006$ & $1,3 \times 10^{1}$ & $4 \times 10^{0}$ & $2,2 \times 10^{1}$ & $1,4 \times 10^{1}$ \\
$29 / 5 / 2006$ & $8 \times 10^{0}$ & $4 \times 10^{0}$ & $1,4 \times 10^{1}$ & $1,2 \times 10^{1}$ \\
$12 / 6 / 2006$ & $9 \times 10^{0}$ & $4 \times 10^{0}$ & $1,7 \times 10^{1}$ & $1,4 \times 10^{1}$ \\
$26 / 6 / 2006$ & $8 \times 10^{0}$ & $6 \times 10^{0}$ & $1,3 \times 10^{1}$ & $1,1 \times 10^{1}$ \\
$10 / 7 / 2006$ & $7 \times 10^{0}$ & $<3 \times 10^{0}$ & $1,4 \times 10^{1}$ & $<3 \times 10^{0}$ \\
$24 / 07 / 2006$ & $9 \times 10^{0}$ & $7 \times 10^{0}$ & $1,7 \times 10^{1}$ & $1,3 \times 10^{1}$ \\
\hline Médias & $9^{\mathbf{a}}$ & $\mathbf{5}^{\mathbf{a}}$ & $\mathbf{1 6}^{\mathbf{b}}$ & $\mathbf{1 1}^{\mathbf{b}}$ \\
\hline
\end{tabular}

a Há diferença significativa $\left(\mathrm{p}=0,0007 ; \mathrm{GL}=12 \mathrm{e} \mathrm{t}_{\mathrm{crt}}=4,524\right)$;

b Há diferença significativa com $\left.\mathrm{p}=0,0250 ; \mathrm{GL}=12 \mathrm{e} \mathrm{t}_{\mathrm{crt}}=2,560\right)$.

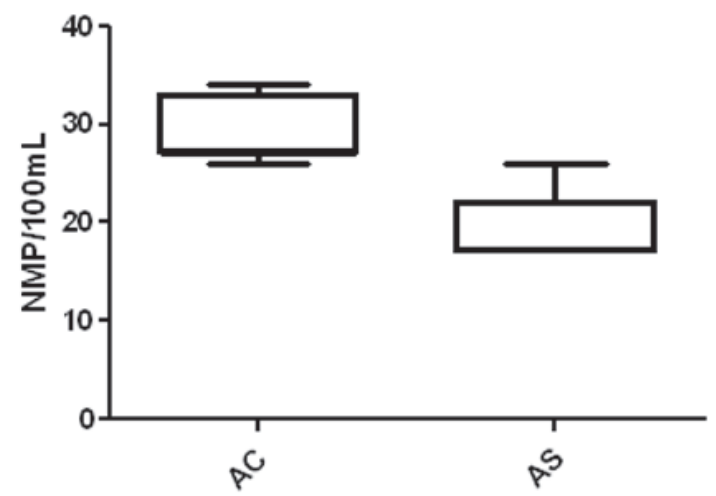

Figura 2 - Análise de Números Mais Prováveis (NMP) de coliformes termotolerantes em águas dos Rios Cachoeira e Santana ( $\mathrm{p}<0,0005 ; \mathrm{GL}=12$ e t $=4,768$ ), Ilhéus-BA, maio a julho de 2006. AC = Água do Rio Cachoeira; AS = Água do Rio Santana; GL = graus de liberdade 
dos pelos dois rios. Além disso, Fidelman ${ }^{2}$ relatou que a ocupação e os usos da terra com práticas agropecuárias inadequadas e desmatamentos nos arredores da bacia também interferem na composição de poluentes e na degradação dos recursos hídricos.

Outros autores, por meio de análises físico-químicas, também têm demonstrado altos índices de poluição no rio Cachoeira. Pinho ${ }^{17}$ encontrou concentrações de fósforo, oxigênio dissolvido, demanda bioquímica de oxigênio e coliformes fora dos padrões estabelecidos pela Resolução CONAMA 020/86 ${ }^{18}$ para rios de água salobra, principalmente, na porção inferior desta bacia. Entretanto, os valores de coliformes totais $(\mathrm{Ct})$, tanto no rio Cachoeira quanto no rio Santana foram inferiores a $5000 \mathrm{Ct} / 100 \mathrm{~mL}$ (Tabela 1), logo estariam classificados como satisfatórios, segundo essa mesma Resolução. Em 2000, foi estabelecido que o número máximo de coliformes termotolerantes seria de $1000 \mathrm{CT} / 100 \mathrm{~mL}$ e esses parâmetros foram corroborados em resolução posterior (CONAMA no 357,2005$)^{19}$.

A adoção do critério de contagem de CT e a exclusão do critério $\mathrm{Ct}$, visando à caracterização da balneabilidade da água, provavelmente se deve à maior capacidade do primeiro tipo de análise em indicar microrganismos patogênicos, os quais causariam a inviabilidade para recreação de contato primário. Dessa forma, para esse aspecto, as águas dos rios Cachoeira e Santana foram classificadas como próprias (Figura 2). Cabe ressaltar, ainda, que há outros fatores para determinar a balneabilidade de águas salobras e que as coletas de água foram realizadas em áreas estuarinas, ou seja, áreas do rio onde existe influência marinha. Segundo Hagler e Hagler ${ }^{20}$, os coliformes têm pouca tolerância à salinidade.

A contagem de CT deveria ser mais representativa em moluscos do que na água, devido ao caráter filtrador dos bivalves. Sua anatomia favorece a acumulação de partículas alimentares, seja por sucção direta, seja pelas correntes d' água provocadas pelo processo respiratório branquial do animal ${ }^{21}$. Scott e Lawrence ${ }^{22}$ sugerem o uso de ostras para monitoramento de zonas costeiras de maneira suplementar às análises de estimativas bacterianas em águas. Nesse estudo, foram utilizados ostras e moapens com esse intuito, por meio da técnica do NMP para detecção de CT, sendo que a investigação acerca da contaminação microbiológica de rios utilizando a prospecção dos moluscos Tagelus plebeius trata-se de uma inovação. Esta espécie, juntamente com a Crassostrea rhizophorae, representa uma parcela de moluscos de interesse econômico que habita o infralitoral raso, os baixios entremarés e os manguezais da região, sendo consumidos e comercializados pelas comunidades ribeirinhas locais ${ }^{23}$. Contudo, os dados encontrados mostram que, no rio Cachoeira, a água apresentou um grau de contaminação fecal estatisticamente superior a ambos os moluscos (Figura 3) e não foi encontrada correlação entre a água e as ostras $(\mathrm{r}=0,316 ; \mathrm{p}=0,49)$, assim como entre a água e os moapens $(\mathrm{r}=0,384 ; \mathrm{p}=0,395)$, sinalizando a inviabilidade de aplicação destes como bioindicadores de poluição nessa localidade. Entretanto, estudos com períodos de amostragem mais prolongados tornam-se importantes, uma vez que as condições do ambiente podem sofrer alterações em função de vários fatores, como por exemplo, variações das marés, das chuvas, entre outras.

Para o rio Santana, os resultados foram semelhantes, com grau de contaminação fecal maior na água que para ambos os bivalves (Figura 4). Além disso, também não houve correlação entre a água e as ostras $(\mathrm{r}=0,264 ; \mathrm{p}=0,567)$ e nem entre água e moapens ( $\mathrm{r}$ $=0,668 ; \mathrm{p}=0,101)$. Estes resultados corroboram com os dados de Vieira et al. ${ }^{24}$, que indicaram uma maior contaminação na água do que no molusco.

Os dados de CT para água apontam para a possibilidade de classificar os dois rios como adequados para atividade de extrativismo de moluscos. Essa informação é pertinente, visto que estes são utilizados para a subsistência da população ribeirinha e para fins lucrativos, principalmente durante a alta esta- 


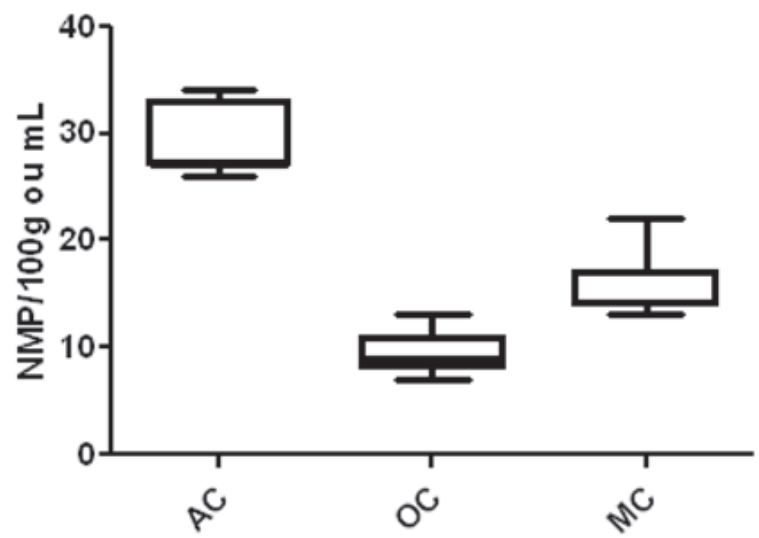

Figura 3 - Análise de Números Mais Prováveis (NMP) de coliformes termotolerantes em águas dos Rios Cachoeira $(\mathrm{p}<0,0001 ; \mathrm{GL}=20) . \mathrm{AC}=$ água do rio Cachoeira; $\mathrm{OC}=$ ostra do rio Cachoeira; $\mathrm{MC}=$ moapem do rio Cachoeira; $\mathrm{GL}=$ graus de liberdade

ção, quando costumam ser consumidos in natura. A lei nacional vigente, Resolução - RDC no 12 , de 2 de janeiro de $2001^{3}$, da Agência Nacional de Vigilância Sanitária (Anvisa), estabelece tolerância para quantidade de CT de até 5 x $10 \mathrm{UFC/g}$. Diferente desta, na regulamentação internacional, a FDA (Food and Drug Administration) instituiu que não devem ser encontrados mais do que $230 \mathrm{NMP}$ de $\mathrm{CT} / \mathrm{g}$ de ostra. Aplicando essa determinação de modo estendido, todos os bivalves analisados estavam dentro de padrões aceitáveis tanto em âmbito nacional quanto internacional (Tabela 2).

Por meio da contagem padrão em placa de moluscos e água, foram isolados um total de 68 microrganismos, classificados em oito gêneros e dez espécies, a saber Citrobacter freundii, Enterobacter agglomerans, Enterobacter cloacae, Escherichia coli, Pantoea agglomerans, Providencia rettgeri, Providencia sp.,

\section{Referências}

1.VALENÇA, J. F. S. Rio Salgado: agente de agravos à saúde das populaçõ̂es ribeirinhas. 2003. 109 f. Dissertação (Mestrado em Desenvolvimento Regional e Meio Ambiente) - Universidade Estadual de Santa Cruz, Ilhéus, 2003.

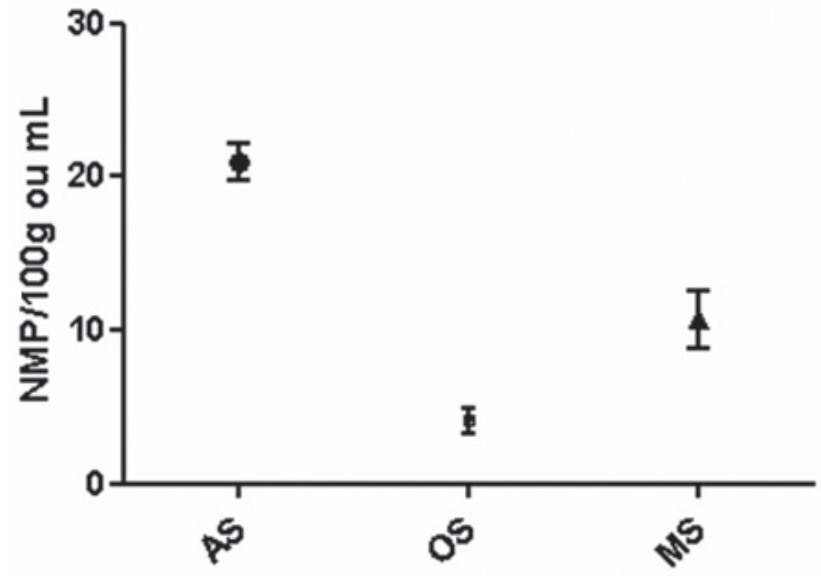

Figura 4 - Análise de Números Mais Prováveis (NMP) de coliformes termotolerantes (CT) em águas dos Rios Santana $(\mathrm{p}<0,0001 ; \mathrm{GL}=20)$. AS = água do rio Santana; OS = ostra do rio Santana; $\mathrm{MS}=$ moapem do rio Santana; $\mathrm{GL}=$ graus de liberdade

Salmonella typhi, Serratia rubidaea e Shigella sp. Às despensas da conformidade determinada mediante legislações vigentes, a patogenicidade de algumas dessas bactérias identificadas alerta para o risco do consumo in natura desses moluscos.

A prospecção de moluscos para o acompanhamento dos índices de poluição não se mostrou efetiva considerando a pesquisa de CT em ostras e moapens neste estudo, entretanto, investigações em outras épocas e com outras espécies são sugeridas. Apesar de os rios Cachoeira e Santana terem apresentado valores de coliformes dentro dos níveis aceitos pela legislação vigente, a presença de bactérias patogênicas evidenciadas no estudo, com potencial para desencadear agravos à saúde humana, reforça a importância de monitoramentos constantes das condições microbiológicas da região e por períodos de amostragem mais prolongados.

2.FIDELMAN, P. I. J. Contribuição para a mitigação dos impactos da macrófita aquática Eichhornia crassipes sobre a zona costeira da região Sul da Bahia. Gerenciamento Costeiro Integrado, v. 4, p. 01-05, 2005. 
3.AGÊNCIA NACIONAL DE VIGILÂNCIA SANITÁRIA. Resolução - RDC N ${ }^{\circ} 12$, de 2 de janeiro de 2001. Regulamento técnico sobre os padrões microbiológicos para alimentos. Diário Oficial [da] República Federativa do Brasil, Brasília, DF, 10 jan. 2001. Disponível em: <http://www.anvisa.gov.br/ legis/resol/12-01rdc.htm>. Acesso em: 11 jan. 2009.

4.PRUZZO, C.; GALLO, G.; CANESI, L. Persistence of vibrios in marine bivalves: the role of interactions with haemolymph components. Environmental Microbiology, v. 7, n. 6, p. 761$772,2005$.

5.LEAL, D. A. G.; FRANCO, R. M. B. Moluscos bivalves destinados ao consumo humano como vetores de protozoários patogênicos: metodologias de detecção e normas de controle. Revista Panamericana de Infectologia, v. 10, n. 4, p. 48-57, 2008.

6.CARVAlHO, C. E. V.; CAVAlCANTE, M. P. O.; GOMES, M. P.; FARIA, V. V.; REZENDE, C. E. Distribuição de metais pesados em mexilhões (Perna perna, L.) da Ilha de Santana, Macaé, SE, Brasil. Ecotoxicology Environmental Rest, v. 4, n. 1, p. 1-5, 2001.

7.GALVÃO, J. A. Qualidade microbiológica da água de cultivo e de mexilhões Perna perna (Linnaeus, 1758) comercializados em Ubatuba, SP. 2004. 109 f. Dissertação (Mestrado em Ciência e Tecnologia de Alimentos) - Escola Superior de Agricultura Luiz de Queiroz, Piracicaba, 2004.

8.SILVA, A. I. M.; VIEIRA, R. H. S. M.; MENEZES, F. G. R.; FONTELES-FILHO, A. A.; TORRES, R. C. O.; SANT'ANNA, E. S. Bacteria of fecal origin in mangrove oysters (Crassostrea rhizophorae) in the Cocó river estuary, Ceará State, Brazil. Brazilian Journal of Microbiology, v. 34, p. 126-130, 2003.

9.COOK, D. W. Fate of enteric bacteria in estuarine sediments and oyter feces. Journal Mississippi Academy of Sciences, v. 29, p. 71-76, 1984.

10. ROWSE, A. J.; FLEET, G. H. Viability and release of Salmonela charity and Escherichia coli from oyters feces. Applied and Environmental Microbiology, v. 44, p. 544-548, 1982.

11.CROCI, L.; SUFFREDINI, E.; COZZI, L.; TOTI, L. Effects of depuration of molluscs experimentally contaminated with Escherichia coli, Vibrio cholerae $\mathrm{O} 1$ and Vibrio parahaemolyticus. Journal of Applied Microbiology, v. 92, p. 460-465, 2002.

12.PEREIRA, M. A.; NUNES, M. M.; NUERNBERG, L.; SCHULZ, D.; BATISTA, C. R. V. Microbiological quality of oysters (Crassotrea gigas) produced and commercialized in the coastal region of Florianópolis - Brazil. Brazilian Journal of Microbiology, v. 37, p. 159-163, 2006.

13. BERGEY, L. C. Manual of systematic bacteriology. Baltimore: Williams \& Wikins, 1986.

14. GARTHRIGHT, W. E. Bacteriological analytical manual. 8. ed. Food and Drug Administration - FDA /Center for Food Safety and Applied Nutrition - CFSAN. 1998. Disponível em: <http:// www.cfsan.fda.gov/ ebam/bama2.html $>$. Acesso: 10 ago. 2009.
15.SALÁN, E. O. Tratamento térmico de mexilhões Perna perna como forma de assegurar a qualidade - Avaliação do crescimento de Bacillus cereus e Staphylococcus aureus. 2005. 88 f. Dissertação (Mestrado em Ciência e Tecnologia de Alimentos) - Escola Superior de Agricultura Luiz de Queiroz, Piracicaba, 2005.

16.SCHNEIDER, R. N.; NADVORNY, A.; SANTOS, M. A. A.; SCHMIDT, V. Caracterização da microbiota mesófila aeróbia de águas superficiais e subterrâneas da microbacia do Lajeado Suruvi. Acta Scientiae Veterinariae, v. 36, p. 7-12, 2008.

17. PINHO, A. G. Estudo da qualidade das águas do rio cachoeira - região sul da Bahia. 2001. 110 f. Dissertação (Mestrado em Desenvolvimento Regional e Meio Ambiente) Universidade Estadual de Santa Cruz, Ilhéus, 2001.

18. CONSELHO NACIONAL DO MEIO AMBIENTE. Resolução $\mathrm{n}^{\circ} 20$ de 18 de junho de 1986. Resolve estabelecer a classificação das águas doces, salinas, salobras do território nacional segundo seus usos preponderantes. Diário Oficial da União, Brasília, 18 jun. 1986. p. 11356-11361. Disponível em < www. mma.gov.br/port/conama/res/re. s86/res2086.html>. Acesso em: 30 jan. 2009.

19. CONSELHO NACIONAL DO MEIO AMBIENTE. Resolução $n^{\circ} 357$ de 17 de março de 2005. Dispõe sobre a qualidade dos corpos de água e diretrizes ambientais para o seu enquadramento, bem como estabelece as condições e padrões de lançamentos de efluentes e dá outras providências. Diário Oficial da União, Brasília, 17 mar. 2005. n. 53, Sec. 1, p. 58-63. Disponível em: <http://www.mma.gov.br/conama/res/res05/ res35705.pdf. >Acesso em: 6 jul. 2009.

20.HAGLER, A. N.; HAGLER, L. C. S. M. Indicadores microbiológicos de qualidade sanitária, In: ROITMAN, I.; TRAVASSOS, L. R.; AZEVEDO, J. L. Tratado de microbiologia. São Paulo: Manole, 1988. v. 1, p. 88-96.

21.HICKMAN JR., C. P.; ROBERTS, L. S.; LARSON, A. Princípios integrados de zoologia. 11. ed. Rio de Janeiro: Guanabara Koogan, 2004. 846 p.

22.SCOTT, G. I.; LAWRENCE, D. R. The american oyster as a pollution monitor: a pilot coastal zone study. Estuaries, v. 5, n. 1, p. $40-46,1982$.

23.PINTO, T. R.; BOEHS, G. Nematopsis sp. (Apicomplexa: Eugregarinida) em Mytella guyanensis (Lamarck, 1819) (Bivalvia: Mytilidae) da Região Estuarina do Rio Cachoeira, Ilhéus, Bahia, Brasil. Brazilian Journal Veterinary Research Animal Science, v. 45, n. 2, p. 95-100, 2008.

24.VIEIRA, R. H. S. F.; ATAYDE, M. A.; CARVALHO, E. M. R.; CARVALHO, F. C. T.; FONTELES FILHO, A. A. Contaminação fecal da ostra Crassostrea rhizophorae e da água de cultivo do estuário do rio Pacoti (Eusébio, Estado de Ceará): Isolamento e identificação de Escherichia coli e sua susceptibilidade a diferentes antimicrobianos. Brazilian Journal Veterinary Research Animal Science, v. 45, n. 3, p. 180-189, 2008. 